\title{
MATHEMATICS RESULTS OF LATVIA FIRST YEAR ENGINEERING STUDENTS AT REMOTE STUDIES AND COVID PANDEMIA TIME
}

\author{
Evija Kopeika ${ }^{1}$, Liga Zvirgzdina ${ }^{2}$ \\ ${ }^{1}$ Riga Technical University, Latvia; ${ }^{2}$ Latvia University of Life Sciences and Technologies, Latvia \\ evija.kopeika@rtu.lv, liga.zvirgzdina@1lu.lv
}

\begin{abstract}
In Latvia, the "Competencies approach to learning content" project is being implemented (Skola2030), which, inter alia, also reforms the field of math teaching and is expected to bring students to the knowledge, skills and attitudes needed for life today. Investment in education and lifelong learning is an essential prerequisite for economic development and for promoting national competitiveness, as well as for achieving higher levels of prosperity. One of the main objectives of the survey was to clarify the relationship between the assessment of the students' annual score by graduating the school and the results of the state exam, as well as the relationship with the result of the first semester of study and the assessment of the semester, both in Latvia as a whole and depending on the students' place of residence. Continuing previous studies, RTU and LLU researchers have conducted extensive surveys of students between 2019 and 2020 to assess the dynamics of the development of teaching performance in math in the changing circumstances of Covid19 in the pandemic. The article reflects the results of a study on the dynamics of the level of knowledge of engineering students in math, as well as the development of the level of knowledge in this field during studies. The article summarises the results of studies, identifies major challenges. In view of the results obtained, it would be desirable that higher education institutions, applying budget places for young students, would place more weight on the math assessment obtained at school.
\end{abstract}

Keywords: engineering education, mathematics results, remote studies.

\section{Introduction}

The demand for engineering professionals in the labour market is significantly higher than the supply. On the other hand, all engineering professionals need a high level of knowledge in the sciences in order to be able to perform their duties qualitatively, but more so as to develop complex and innovative projects.

The skills and competences of mathematics - which are part of STEM fields - have been recognised in the European Union as one of the most important competences in the education of engineers and in the development of a successful professional career in the knowledge society of the $21^{\text {st }}$ century. Worldwide, there is a growing interest in $21^{\text {st }}$ century skills and opportunities for their inclusion in the education system. As one of the solutions is critical thinking in the learning process, and math is one of the drivers of critical thinking.

There are many studies on both the labour market need for highly educated engineers and the role of mathematics in the education of young engineers. This has been proven by many scientists and recognized by the European Society for Engineering Education.

Engineering education has a very important role in society, bridging the gap between the world of today and education, and addressing local, regional and global challenges. The new professional not only needs to be knowledgeable in his/her own discipline, but also needs a new set of soft, professional skills and competencies [1]. Mathematics has been regarded as a fundamental knowledge area.

The European Society for Engineering Education has defined mathematical competence by defining the A Framework for Mathematics Curricula in Engineering Education, - mathematical competence is the ability to understand, judge, do, and use mathematics in a variety of intra and extra mathematical contexts and situations in which mathematics plays or could play a role [2;3].

Latvia is in the reform phase of the school education program. The aim of the project entitled "Competencies approach in learning content" (Skola2030), implemented by the National Education Content Centre (VISC), is to develop, empathize, implement in Latvia the content of general education and the approach to teaching from pre-school to secondary school, resulting in pupils acquiring the necessary knowledge, skills and attitudes for life today. This project reforms the field of math teaching, and it is expected to bring student to the knowledge, scraps and attitudes needed for life today [4]. 
The teachers working with the first-year students often meet with the problem that the new students do not have equal level of preliminary knowledge. Qualitative engineering studies are not possible without profound preparation in mathematics [5].

Mathematics is fundamental for many professions, especially science, technology, and engineering. Yet, mathematics is often perceived as difficult and many students leave disciplines in science, technology, engineering, and mathematics (STEM) as a result, closing doors to scientific, engineering, and technological careers [6].

As a worrying process, it should be noted that every year a large number of engineering specialist students in Latvia are leaving their studies in the first year, indicating as a reason insufficient math preparedness and inability to learn a math program in the higher education institution.

It is reported that mathematics is the "the key academic hurdle" in the supply of engineering graduates [7].

The authors of the article, like other Latvian educators and researchers, are concerned about the students' not very good knowledge in math and their lack of preparedness in STEM field subjects in general. The results of the centralised exams are not very pleasing in Latvia, particularly in math, where they are declining from year to year [8].

From March 2020 to the spring of 2021, the whole world faced serious challenges for the Covid-19 pandemic. In Latvia, the major part of this period for both pupils and students the training process took place in remote mode. Consequently, the authors of this article became interested in studying the results of these remote trainings for engineering students at such an important STEM field subject as mathematics.

\section{Materials and methods}

The authors from two universities (RTU and LLU) carried out a survey of engineering students in 2019 and again in 2020. In 2019, 275 RTU students, 103 LLU students and 46 RTK participated in the survey, while in 2020, - 281 RTU students, 56 LLU students and 35 RTK first year to fourth year students.

Table 1

Distribution of respondents in the survey depending on their affiliation to the university

\begin{tabular}{|c|c|c|c|c|}
\hline $\begin{array}{c}\text { Higher education } \\
\text { institution }\end{array}$ & \multicolumn{2}{|c|}{ Absolute values } & \multicolumn{2}{c|}{ Percentage } \\
\hline Year & $\mathbf{2 0 1 9}$ & $\mathbf{2 0 2 0}$ & $\mathbf{2 0 1 9}$ & $\mathbf{2 0 2 0}$ \\
\hline RTU & 275 & 281 & $65 \%$ & $76 \%$ \\
\hline LLU & 103 & 56 & $24 \%$ & $15 \%$ \\
\hline RTK & 46 & 35 & $11 \%$ & $9 \%$ \\
\hline Total & 423 & 372 & $100 \%$ & $100 \%$ \\
\hline
\end{tabular}

When comparing the results of the survey of representatives of different institutions, they were uniform and equivalent. The authors did not carry out an expanded analysis of the data of individual institutions in this particular study. Then, according to the number of engineering students in Latvia, separate small datasets would be created. On the other hand, the results could not be generalized and would not be statistically comparable. Consequently, the authors work with the whole set of students at the same time, as well as using the distribution of students by place of residence.

Study data were processed by developing regression analysis models. Durbin-Watson test and Goldfeld- Kvand test were used for assessing the significance of models and for error analysis. For the credibility and safety of the results a heteroscedasticity assessment was carried out, both with a graphic and Goldfeldt-Kvand test, to check whether the variances of errors at each assessment were the same. The Durbin-Watson test also examined the likelihood of autocorrelation (i.e. whether the errors correlate with each other).

\section{Results and discussion}

Since comprehensive skills in mathematics and the ability to focus on different challenges and find solutions to them are one of the essential requirements for an engineering specialist to be highly 
qualified, the authors continue to study the level of student preparedness when enrolling in a growing school, continuing to learn and assess the actual level of knowledge.

For example, in order for electronics an energy engineer is able to qualitatively develop efficient, economic and customer-friendly electrical circuit models, he should be well acquainted with partial derivatives and differentials. To study the operation of different fields (such as a magnetic field), both their operating intervals and what to do to minimise them, you need to be familiar with both surface integrals and flow theory. There are a lot of such examples.

Many will say that there are a number of serious computer programs for both design and calculation, such as Autocad, Mathcad, Solitwork and others, which can both design and calculate what is needed. However, without the understanding and ability of the author's basic communications to justify them, as well as the skills to simultaneously forecast a number of project development scenarios from which the most suitable project or calculation complex is developed cannot be considered to be reliable [9].

It is increasingly difficult to prepare such qualified professionals in higher education, given that the level of training of young first year students is becoming less and less mature when starting. In addition, a large part of first-year students lack an understanding of the role of physical knowledge in the study process, not to mention their role in the development of logical thinking in general.

One of the main objectives of the survey was to clarify the relationship between the assessment of the students' annual score by graduating the school and the results of the state exam, as well as the relationship with the result of the first semester of study and the assessment of the semester, both in Latvia as a whole and depending on the students' place of residence.

The results of the state examinations showed a specific characteristic. It has been proven that school graduates avoid participating in the whole math exam. The exam is organized in several parts, and a large proportion of graduates do not participate in the execution of all parts of the math exam [8]. As a result, the assessment of the state exam does not fully reflect students' knowledge in mathematics.

Unfortunately, like in the 2019 study, a statistically significant relationship between the results of the state exam and the results in math during the studies failed to be found this year.

On the other hand, the relationship between school year ratings and grade in the first exam at the higher educational institution is shown in Fig. 1.

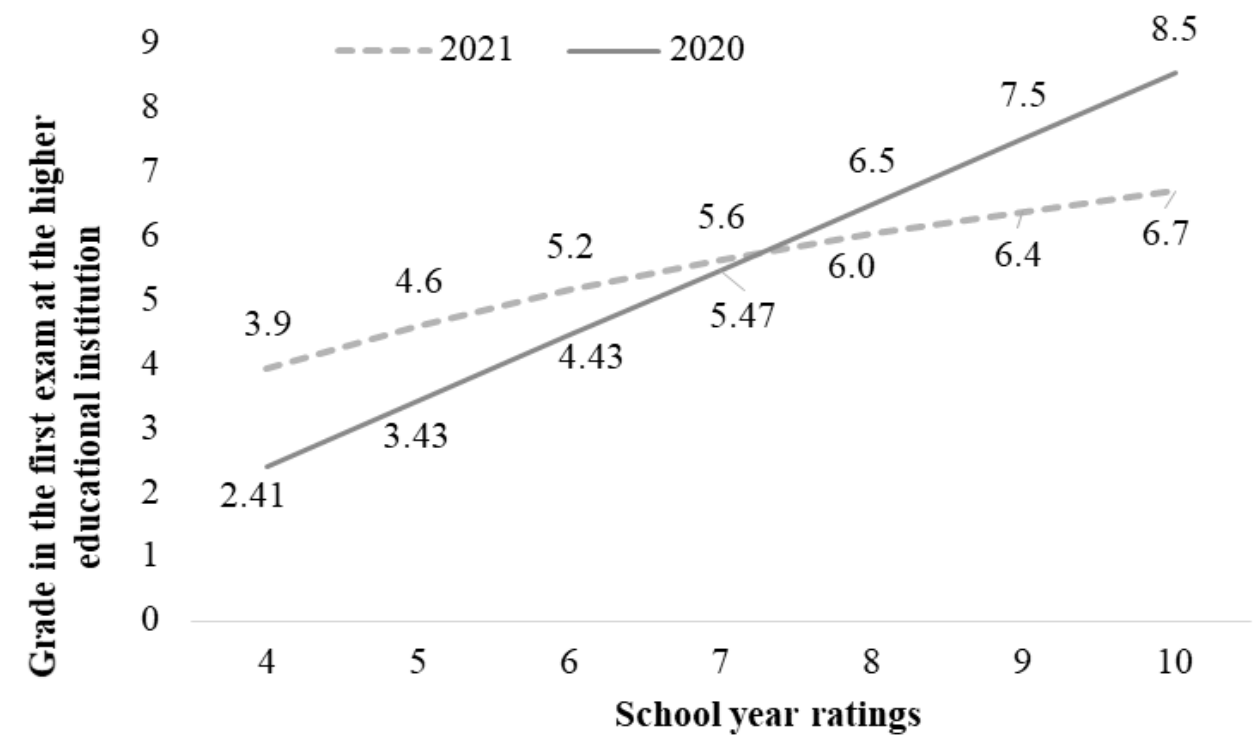

Fig. 1 Regression trendlines for the first exam score at the higher education institution depending on the students' annual score by graduating school (engineering students) in 2019 and 2020

As shown in Fig. 1, the score trends have changed in 2020 compared to 2019.

$$
\begin{gathered}
y=-1.67+1.02 x, \\
\left(R^{2}=0.72 ; \text { Sig. }=0.00\right)
\end{gathered}
$$


where $x$-assessment received at school;

$y$ - results of the first semester 2019 [9].

$$
\begin{aligned}
& y=-0.26+3.025 \ln (x), \\
& \left(R^{2}=0.68 ; \text { Sig. }=0.00\right)
\end{aligned}
$$

where $\mathrm{x}$-assessment received at school;

$y$ - results of the first semester 2020 .

The model developed from the 2020 survey, although at $95 \%$ confidence, represents only $68 \%$ of potential results and is with slightly lower credibility as the result of 2019 , is statistically significant.

For the credibility and safety of the results, a heteroscedasticity assessment was carried out, both with a graphic and Goldfeldt-Kvand test, to check whether the variances of errors at each assessment were the same.

Using Goldfeld-Kwand test, the calculated value $F_{\text {nov }}=0.985$ was compared to the theoretical

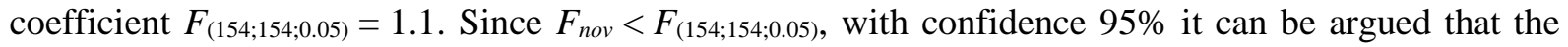
heterogeneity problem does not exist.

The results of both tests clearly indicate that there is no problem with heterogeneity in this model.

The Durbin-Watson test also examined the likelihood of autocorrelation (i.e., whether the errors correlate with each other). So, in the given model DW $=1.93$ (Durbin-Watson d-statistics) and theoretical coefficients, depending on the size 372 and number of factors (1), are $-d_{\text {Lower }}=1.77$, but $d_{\text {Upper }}=1.78$.

Since $d_{\text {Upper }}<D W<d_{4-\text { Upper }}$, with confidence $95 \%$, it can be argued that the heterogeneity problem does not exist. So, errors do not correlate with each other and do not produce false results.

Thus, when comparing the results of the models in the 2019 and 2020 studies, the following trend appears, - the result of the first exam at the higher education institutions is similar, that is, the result obtained at the higher education institution is on average 1 to 2 grades lower than that obtained at school.

Trends are different in the lower rating group and the highest rating group. If school grades up to 6 balls, the first-year students in 2020 have a higher estimated score compared to the previous year, then the 8 balls and more school grades are the opposite.

This result could have a number of clarifications. One of the explanations is, - a training model that was involved because of the Covid-19 restrictions, - and only remote training was organized in schools from March 2020. In this context, students who were also hard at learning math, at this time, when learning the new topics and then revising of topics was mostly to be done independently, were unable to do it properly.

It should be noted that it is very difficult to learn the exact subjects independently, sometimes impossible. Teenage pupils probably lacked patience, too. Students could also miss advice because parents could not provide quality advice, such as learning math topics. As a result, the school closing results declined.

In the autumn of 2020, when students started their studies, the practice sessions were organised onsite by the RTU up to the 1st exam, while even all of the lessons were on-site in the LLU and RTK. This resulted in a large part of the first year students greatly improving their knowledge and working hard on improving results, thanks to both presence and in addition to counselling at the higher education institution, as well as the revising of the key topics. On the other hand, students who had higher annual grades at school say they had burned out in their own preparation for school closings, they felt overwrought. At the university, it has been difficult for such students to focus on learning topics again.

For a more detailed study of the situation the authors of the article carried out an analysis of the data of the survey conducted in 2021, taking into account the respondents' place of residence (Riga, small-town, rural area), the results are summarised in Fig. 2. In Fig. 2 all lines are regression analysis results. The description of the results is added in Table 2 . 


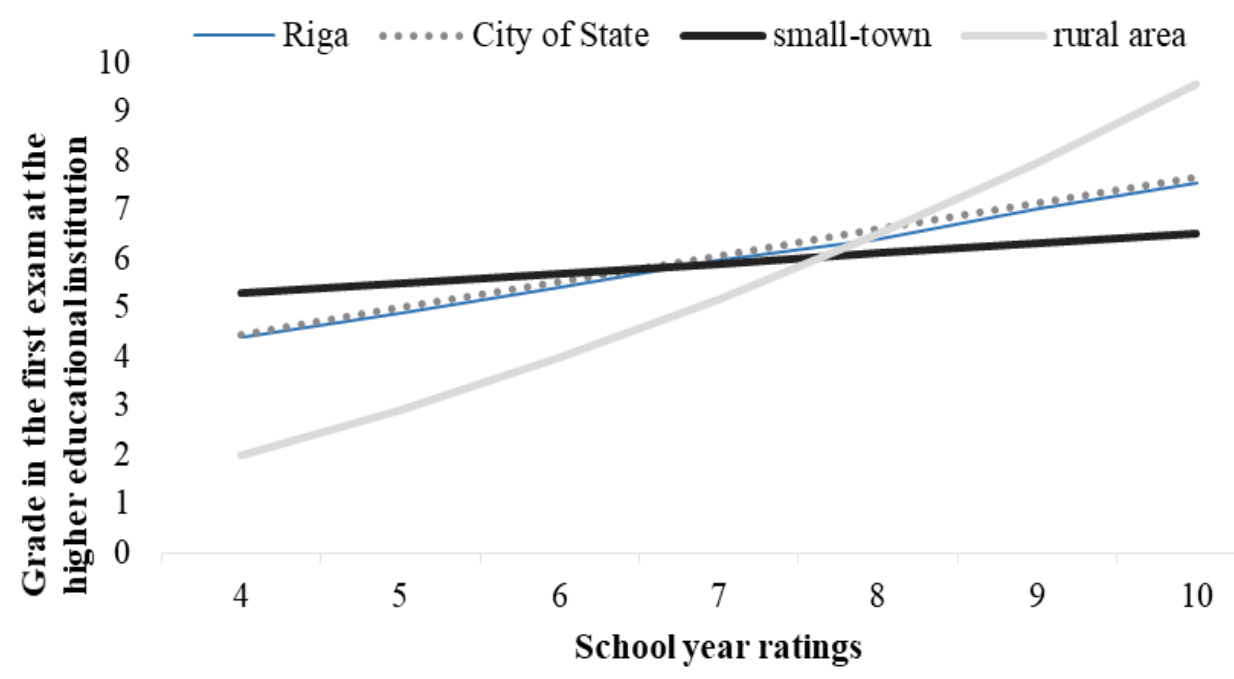

Fig. 2. Regression trendlines for the first semester results at the higher education institution (engineering students) depending on the annual assessment, taking into account the respondents' place of residence, 2020

Table 2

Regression models for the first semester results at the higher education institution (engineering students) depending on the annual assessment, taking into account the respondents' place of residence, 2020, the results of the most important tests of statistical significance

\begin{tabular}{|c|c|c|c|c|}
\hline $\begin{array}{c}\text { Place of } \\
\text { residence }\end{array}$ & Model & $\begin{array}{c}\text { Coefficient of } \\
\text { determination } \\
\text { (p-value }- \\
\mathbf{0 . 0 0 )}\end{array}$ & $\begin{array}{c}\text { Durbin-Watson test } \\
\text { (value DW) }\end{array}$ & Goldfeld- Kvand test \\
\hline Latvia & $y=-0.27+3.03 \ln (x)$ & 0.68 & $d_{\text {Upper }}<1.93<d_{4-\text { Upper }}$ & $F_{\text {nov }}=0.985<F_{(154 ; 154 ; 0.05)}=1.1$ \\
\hline Riga & $y=2.22+0.53 x$ & 0.71 & $d_{\text {Upper }}<2.04<d_{4-U p p e r}$ & $F_{\text {nov }}=1.18<F_{(59 ; 59 ; 0.05)}=1.53$ \\
\hline $\begin{array}{c}\text { City of } \\
\text { State }\end{array}$ & $y=2.32+0.53 x$ & 0.67 & $d_{\text {Upper }}<1.92<d_{4-\text { Upper }}$ & $F_{\text {nov }}=1.21<F_{(43 ; 43 ; 0.05)}=1.69$ \\
\hline $\begin{array}{c}\text { Small } \\
\text { town }\end{array}$ & $y=3.56+0.38 x$ & 0.74 & $d_{\text {Upper }}<1.90<d_{4-U p p e r}$ & $F_{\text {nov }}=1.6<F_{(24 ; 24 ; 0.05)}=1.98$ \\
\hline $\begin{array}{c}\text { Rural } \\
\text { area }\end{array}$ & $\ln (y)=-1.69+1.72 \ln (x)$ & 0.82 & $d_{\text {Upper }}<2.06<d_{4-U p p e r}$ & $F_{\text {nov }}=1.87<F_{(23 ; 23 ; 0.05)}=2.01$ \\
\hline
\end{tabular}

As we see, in the Table 2 the relationship between the results studied in all models considered is statistically significant with $95 \%$ confidence, in which neither heteroscedasticity nor autocorrelation risks exist (Table 2).

It is interesting that the results are statistically insignificant in Riga and cities of state, so the results are equally predictable. The trend in small towns is similar to that at the national level - there are differences between this and previous year results, for which reasons could also be equivalent. On the other hand, the representatives of rural areas tendencies differ significantly.

\section{Conclusions}

Unfortunately, like in the 2019 study, a statistically significant relationship between the results of the state exam and the results in math during the studies failed to be found this year. Comparing the results of the models in the studies, the following trend appears, - the effect of the school closing grade on the first exam in higher education institution in both study years is similar. Trends are different in the lower rating group and the highest rating group. In Riga and cities of state the results are equally predictable, on the other hand, the representatives of rural areas tendencies differ. In view of the results obtained, it would be desirable that higher education institutions, applying budget places for young students, would place more weight on the math assessment obtained at school. 


\section{References}

[1] Morell L. Engineering Education in the 21st Century: Roles, Opportunities and Challenges. [online] [27.03.2021] Available at: https://luenymorell.files.wordpress.com/2010/12/morell-eng-edu-in21st-cent-roles-opport-and-challenges.pdf

[2] A Framework for Mathematics Curricula in Engineering Education. European Society for Engineering Education (SEFI). Brussels. OSEFI 2013 [online] [20.02.2021]. Available at: http://sefibenvwh.cluster023.hosting.ovh.net/wp-content/uploads/2017/07/Competency-basedcurriculum-incl-ads.pdf

[3] Goold E., Devitt F. The role of mathematics in engineering practice and in the formation of engineers. SEFI 40th annual conference. 23-26 September, 2012, Thessaloniki, Greece. [online] [20.02.2021]. Available at: https://www.researchgate.net/publication/283365709_The_role_of_ mathematics_in_engineering_practice_and_in_the_formation_of_engineers

[4] Skola2030 (School2030) (In Latvian) [online] [29.03.2021]. Available at: https://www.skola2030.lv/lv

[5] Sergejeva N., Aboltins A. Knowledge of Mathematics and Physics as Basis for Studies in Engineering Sciences. Proceedings of the 19th International scientific conference "Engineering for rural development", vol. 19, May 20 - 22, 2020, Jelgava, Latvia, pp. 1302.-1307. [online] [27.03.2021] Available at: http://www.tf.llu.lv/conference/proceedings2020/Papers/TF325.pdf

[6] Li, Y., Schoenfeld, A.H. Problematizing teaching and learning mathematics as "given" in STEM education. IJ STEM Ed 6, 44, 2019. [online] [27.03.2021]. Available at: https://doi.org/ 10.1186/s40594-019-0197-9

[7] Croft T., Grove M. Mathematics Support: Support for the Specialist Mathematician and the More Able Student, MSOR Connections, vol. 6, 2006, No. 2, pp. 1-5.

[8] Valsts pārbaudes darbi. Statistika. (National examinations. Statistics). (In Latvian) [online] [29.03.2021]. Available at: https://www.visc.gov.lv/lv/valsts-parbaudes-darbi-statistika

[9] Kopeika E., Zvirgzdina L. Skills and competencies in mathematics of engineering students in context of sustainable development. Proceedings of the 19th International scientific conference "Engineering for rural development", vol. 19, May 20 - 22, 2020, Jelgava, Latvia, pp. 1255.-1261. [online] [27.03.2021] Available at: http://www.tf.llu.lv/conference/proceedings2020/Papers/ TF303.pdf 